\title{
Penulisan Artikel Ilmiah Berbasis Jurnal Ilmiah Bagi Guru SMP-SMA Kabupaten Lombok Tengah
}

\author{
Arif Rahman, I Ketut Warta, Jupri, Haerazi, Lalu Ari Irawan \\ Dosen IKIP Mataram \\ Arifrahman058020@gmail.com
}

\begin{abstract}
Abstrak; Kegiatan menulis ilmiah merupakan kegiatan yang membutuhkan pemahan dan dan keterampilan menulis secara akademis yangtidak dapat dipisahkan dari profesi guru dan dosen. Khususnya para Guru sebagai pendidik di sekolah tentu keharusan bagi mereka agar dpat mengembangkan profesi melalui tulisantulisan atau karya tulis ilmiah berdasarkan data dan temuan mereka di lapangan dalam aktivitas pendidikan.Namun demikian, sebagian besar mereka belum mampu atau tidak ada akses bagi guru-guru untuk menuangkanya dalam karya tulisan ilmiah berupa artikel jurnal, sehingga dapat menjadi bagian dari pengembangan profesi mereka sebagai pendidik. Berdasarkan pantauan dan hasildiskusi dengan beberapa guru SMP-SMA dan MGMP Bahasa Inggris batukliang Utara kabupaten Lombok Tengah, diketahui bahwa guru mengalami kendala dalam menulis artikel ilmiah dan kurang adanya informasi mengenai jurnal yang akan dituju. Oleh sebab itu, perlu adanya Workshop dan pendampingan lanjutan penulisan artikel ilmiah bagi guru agar bahan yang sudah ada tersebut dapat ditindaklanjuti untuk ditulis dalam format artikel ilmiah. Selain itu, juga perlu adanya informasi bagi guru tentang jurnal-jurnal yang dapat diakses untuk dapat diajukan artikel, baik jurnal nasional maupun jurnal internasional.Target dari program workshop dan pendampingan ini adalah meningkatnya pemahaman dan keterampilan menulis karya ilmiah bagi guru SMP-SMAKabupaten Lombok Tengah tentang jenis-jenis karya ilmiah, kaidah menulis karya ilmiah, dan menulis artikel secara profesional. Luaran dari program pendampingan ini adalah artikel ilmiah yang ditulis oleh guru SMP-SMA Kabupaten Lombok Tengah untuk diajukan ke jurnal nasional atau prosiding seminar nasional. Kegiatan ini diikuti oleh 45 orang guru yang berasal dari empat SMP dan tiga SMA negeri swasta yang berada di wilayah Kecamatan Kabupaten Lombok Tengah. Metode kegiatan yang dilaksanakan guna menyelesaikan permasalahan mitra adalah dengan pendekatan secara klasikal dan individual. Pendekatan klasikal digunakan pada kegiatan penyampaian materi secara teoritik langkah-langkah menulis artikel ilmiah. Pendekatan individual digunakan pada saat peserta pendampingan menulis artikel ilmiah yakni dengan metode workshop. Berdasarkan pelaksanaan kegiatan pendampingan ini, disimpulkan: (1) kemauan peserta dalam menulis artikel atau karya tulis ilmiah adalah cukup tinggi; (2) pemahaman peserta terhadap menulis artikel adalah kurang; dan (3) pemahaman peserta terhadap jenis tulisan adalah kurang. Hasil FGD menujukkan permasalahan yang dialami guru dalam menulis karya ilmiah. Permasalahan yang dialami oleh guru dalam menulis karya ilmiah diklasifikasikan menjadi dua, yaitu masalah eksternal dan masalah internal.Masalah eksternal guru dalam menulis karya ilmiah adalah: (1) kurangnya informasi tentang hal-hal berkaitan dengan menulis; (2) sulitnya menemukan tempat bertanya ketika menulis; (3) keterbatasan referensi dalam menulis; dan (4) proses birokrasi (dibatasi satu jenis tulisan, seperti hasil PTK). Masalah internal guru dalam menulis karya ilmiah adalah: (1) lemahnya budaya menulis di kalangan para guru; (2) rendahnya motivasi guru untuk membuat karya tulis artikel ilmiah; (3) sebagian guru memandang proses birokrasi yang selalu mempersulit membuat mereka menyerah sebelum berusaha; dan (4) keterbatasan waktu untuk menulis.
\end{abstract}

Kata kunci: Workshop dan pendampingan, penulisan artikel ilmiah

\section{PENDAHULUAN}

Kemampuan menulis bagi guru

menjadi tuntutan profesinya. Bagi pengembangan karirnya guru wajib memenuhi syarat berupa penulisan karya ilmiah. Syarat ini seringkali menjadi 
penghambat kenaikan jenjang pangkat bagi guru mengingat rendahnya kemampuan dan minat menulis di kalangan mereka. Selain menjadi syarat bagi pengembangan karir, menulis juga menjadi sarana bagi pengembangan diri seorang guru.Menulis merupakan kegiatan yang tidak dapat dipisahkan dari profesi guru. Guru sebagai pendidik di sekolah tentu memiliki data dan permasalahan yang dapat menjadi sumber dan bahan tulisan. Dengan tulisan itulah, guru dapat menganalisis akar masalah dan gagasan untuk menyelesaikan masalah tersebut. Tulisan yang nantinya dihasilkan oleh guru merupakan upaya mengembangkan profesi guru dalam memahami kegiatan pembelajaran dan sekolahnya. Mengembangkan ilmu pengetahuan tidak lengkap jika hanya berpikir saja, perlu menulis ide-ide, gagasan-gagasan, dan pemikiran tersebut (Gunawan, 2014).

Sehingga perlu adanya sebuah pelatihan untuk mengasah kemampuan menulis guru secara profesional. Writing courses and workshops have beenestablished to help write and avoid inappropriate textual borrowing (Cheng,2008). Many researchers find it extremely difficult to write scientific articles, andfew receive specific training in the art of presenting their research work in written format (Ecarnot, dkk., 2015). Kemampuan menulis memerlukan kemampuanmemahami dan analisis secara mendalam terhadap suatu topik atau fenomena yang menjadi ulasan tulisan. Kemampuan tersebut diperlukan dalam pengembangan karier secara professional(Gilinsky, dkk., 2016). Menulis merupakan salahsatu bentuk pengembangan profesional.

Tulisan yang dimaksud di sini adalah artikel ilmiah. Artikel ilmiah dari karya guru merupakan hal penting dalam pengembangan profesi guru. Thescientific papers is important for scientists because almost all over the world, most journals are written in English or Non-English (Karimnia, 2013). Artikelilmiah merupakan sebuah karangan faktual (nonfiksi) tentang suatu masalah untuk dimuat di jurnal, majalah, atau bulletin dengan tujuan untuk menyampaikan gagasan dan fakta guna meyakinkan, mendidik, dan menawarkan solusi suatu masalah (Komara, 2017). Tulisan artikel ilmiah dapat berasal dari hasil penelitian ataupun kajian teori dengan melakukan analisis secara mendalam

Berdasarkan pantauan dan hasil diskusi dengan beberapa guru SMP-SMA dan MGMP Bahasa Inggris batukliang Utara kabupaten Lombok Tengah, diketahui bahwa guru mengalami kendala dalam menulis artikel ilmiah dan kurang adanya informasi mengenai jurnal yang akan dituju. Oleh sebab itu, perlu adanya Workshop dan pendampingan lanjutan penulisan artikel ilmiah bagi guru agar bahan yang sudah ada tersebut dapat ditindaklanjuti untuk ditulis dalam format artikel ilmiah. Selain itu, juga perlu adanya informasi bagi guru tentang jurnal-jurnal yang dapat diakses untuk dapat diajukan artikel, baik jurnal nasional maupun jurnal internasional.Target dari program workshop dan pendampingan ini adalah meningkatnya pemahaman dan keterampilan menulis karya ilmiah bagi guru SMP-SMAKabupaten Lombok Tengah tentang jenis-jenis karya ilmiah, kaidah menulis karya ilmiah, dan menulis artikel secara profesional. Luaran dari program pendampingan ini adalah artikel ilmiah yang ditulis oleh guru SMP-SMA Kabupaten Lombok Tengah untuk diajukan ke jurnal nasional atau prosiding seminar nasional. Kegiatan ini diikuti oleh 45 orang guru yang berasal dari empat SMP dan tiga SMA negeri swasta yang berada di wilayah Kecamatan Kabupaten Lombok Tengah. Metode kegiatan yang dilaksanakan guna menyelesaikan permasalahan mitra adalah dengan pendekatan secara klasikal dan individual. Pendekatan klasikal digunakan pada kegiatan penyampaian materi secara teoritik langkahlangkah menulis artikel ilmiah. Pendekatan individual digunakan pada saat peserta pendampingan menulis artikel ilmiah yakni dengan metode workshop.

Sangat tepat jika Jurusan Program magister Pendidikan Bahasa InggrisIKIP Mataram melaksanakan kegiatan pendampingan penulisan artikel ilmiah bagi para guru SMP-SMA Kecamatan Batukliang kabupaten Lombok Tengah. Kegiatan workshop dan pendampingan ini akan fokus 
pada strategi menulis artikel ilmiah sesuai dengan standar jurnal ilmiah dan juga akan memberikan informasi mengenai jurnal-jurnal yang dapat diakses, baik untuk rujukan (referensi) dan/atau untuk diajukan artikel ilmiah agar dimuat di jurnal tersebut. Kegiatan workshop dan pendampingan penulisan artikel sangat efektif untuk meningkatkan pemahaman para pendidik.

Workshop dan pendampingan ini ditujukan pada guru-guru SMP-SMAKab. Lombok Tengah. Oleh karena itu, mereka akan mendapatkan manfaat dari kegiatan tersebut, antara lain, adalah sebagai berikut :

1. Memberikan pemahaman kepada guruguru tentang konsep PTI.

2. Memberikan pemahaman kepada guruguru akan pentingnya Artikel Ilmiah.

3. Memberikan bimbingan mengenai apa saja yang perlu dipersiapkan sebelum penelitian dilakukan.

4. Memberikan bimbingan mengenai penyusunan penelitian untuk artikel ilmiah.

5. Memfasilitasi para guru untuk memuat artikel mereka pada Jounal ber ISSN dan SINTA.

Target dari program workshop dan pendampingan ini adalah meningkatnya pemahaman guru SMP-SMA Kabupaten Lombok Tengah tentang jenis-jenis karya ilmiah, kaidah menulis karya ilmiah, dan menulis artikel secara profesional. Berdasarkan target tersebut, pendampingan ini fokus pada pembahasan bagaimana menentukan fokus tulisan, membuat judul artikel, mencari sumber rujukan, menulis artikel, sampai dengan cara mengirim artikel ke jurnal atau ke prosiding seminar. Target artikel yang ditulis peserta adalah $80 \%$ dari peserta yang hadir dalam kegiatan pendampingan.

Kegiatan workshop akan di dilaksanakan di SMPN 2Batukliang Utara Kabupaten Lombok tengah Provinsi Nusa Tenggara barat

Kegiatan Workshop dan Pendampingan menulis karya ilmiah untuk guru-guru SMP se-Kabupaten lombok Tengah ini dilaksanakan pada akhir bulan Maret tahun 2018. Pada pekan ke-tiga bulan Februari
Tahapan kegitan adalah persiapan dan koordinasi. Akhir Bulan Februari adalah sosialisasi Workshop kepada dinas Kab. Lombok Tengah dan guru-guru SMP MGMP. Workshop dilaksanakan pada pekan ke-dua bulan April 2019. dan pendampingan finalisasi artikel ilmiah untuk di terbitkan pada jurnal nasional dan Internasional.

\section{METODE PELAKSANAAN KEGIATAN \\ Metode Pelaksanaan Workshop}

Metode Workshop penulisan karya dan karangan ilmiah ini dilakukan dengan beberapa metode yaitu :

\section{Ceramah}

Pertama pada tahap awal kegiatan Workshop ini di bagi dalam dua sesi yaitu penyajian materi dengan metode ceramah oleh nara sumber yaitu masing -masing; Dr. Jufri, M.Pd, dengan tema " Dr.Arif Rahman, M.Pd, dan Dr. L Ari Irawan, M.Pd tentang materi-materi penulisan karya yaitu (1. Konsep Dasar, Prinsip, dan Model PTK, Penyusunan PTK (Rencana, Metode dan Pelaksanaan PTK, Pentingnya PTK Bagi Pengembangan Profesi Guru, dan prosedur memuat artikel pada jurnal S1 dan S2.), selanjutnya di akhiri dengan sesi tanja jawab.

\section{Diskusi dan Praktik}

Pada tahap kedua kegiatan workshopdilaksanakan dengan metode diskusi dalam mempraktekan penulisan judul proposal PTK. Dalam hal inipeserta workshop dibagi menjadi tiga ruangan dan setiap ruangan dibagi dalam emapt kelompok yang masing masing terdiri dari 5 peserta untuk mendiskusikan materi yang sudah diberikan pelatih. Pada tahap ini setiap kelompok dibimbing oleh satu pendamping untuk mengusulkan dan membuat Judul artikel PTK.

\section{Tahapan Perencanaan Workshop}

Pada tahap perencanaan workshop dilasanakan dalam beberapa tahap dalam rangka persiapan sebagai berikut :

1. Pertama, penyusunan TOR oleh kaprodi Magister Pendidikan Bahasa Inggris

2. Melakukukan lobi kerjasama antara pihak Fakultas FPBS IKIP Mataram dan Pihak Diknas Kabupaten Lombok Tengah 
3. Menyusun rencana kegiatan workshop dan pembentukan panitiapelaksana workshop.

4. Nara sumber menyusun materi workshop yang sudah disesuaikan dengan kebutuhan peserta.

5. Sebelum pelaksanaan kegiatan, panitia melakukan diskusi materi dan TOT serta finalisasi materi workshop.

\section{Tahapan Pelaksanaan Workshop}

Pada tahap ini kegiatan Workshop di bagi dalam dua sesi kegiatan yaitu sesi kegiatan pendahuluan dan sesi kegiatan inti sebagai berikut :

\section{Kegiatan Pendahuluan}

Tahap pendahuluan ini dilakukan dengan beberapa kegiatan yaitu:

a. Registrasi awal peserta

b. Pembukaan oleh MC

c. Pembacaan doa untuk kelancaran Workshop

d. Sambutan-Sambutan oleh Kabid Dikdas, ketua panitia

e. Sambutan Oleh Rektor IKIP Mataram

e. Pemberian materi oleh semua narasumber

\section{Kegiatan Inti}

Tahapan inti dari Workshop dan Pendampingan penulisan karya ini adalah penyajian materi-materi yang sudah dijelaskan dalam silabus Workshop dan Pendampingan yang dibuat. Di dalam silabus memiliki beberapa komptensi dasar dengan harapan peserta Workshop dan Pendampingan menguasai materi-materi yang diberikan dalam Workshop dan Pendampingan ini. Selanjutnya, melakukan pendampingan jarak jauh via On-line kepada peserta dalam kurun waktu tertentu sampaipenulisan artikel menjadi sebuah artikel ilmiah yang siap di muat dalam jurnal FPBS IKIP Mataram dan pada jurnal lainya.

Tahapan Evaluasi Workshop dan Pendampingan

Pada Tahapan akhir Workshop dan Pendampingan ini dilakukan dengan mengadakan evaluasi terhadap materi yang sudah diberikan sebelumnya, dan juga memberikan peserta waktu untuk praktek membuat karya ilmiah agar peserta dapat menguasai materi dan tahu bagaimana cara menyusun proposal dan penelitian hingga artikel ilmiah.

\section{HASIL KEGIATAN}

\section{Jadwal Penelitian}

Kegiatan pendampingan ini dilaksanakan selama tiga hari Aula SMP N 2 Batukliang Utara. Kegiatan ini diikuti oleh 45 orang guru yang berasal dari tiga SMP-SMA yang berada di wilayah Kabupaten Lombok Tengah. Rincian peserta dan asal sekolah adalah SMP sebanyak 25 orang dan SMA 20 orang. Adapun jadwal kegiatan seperti ditampilkan pada Tabel 5.1.

Tabel Jadwal Kegiatan workshop dan Pendampingan

\begin{tabular}{|c|c|c|c|}
\hline $\begin{array}{l}\text { Waktu/ } \\
\text { Durasi }\end{array}$ & Kegiatan & Bobot & Pengisi - Pemateri \\
\hline $08.30-09.00$ & Registrasi Peserta & - & $\begin{array}{c}\text { Panitia } \\
\end{array}$ \\
\hline $09.00-09.30$ & Pembukaan & - & Panitia \\
\hline \multirow[b]{2}{*}{$09.30-11.00$} & Sambutan & $0.5 \mathrm{JPL}$ & Kepala Dinas Loteng \\
\hline & $\begin{array}{l}\text { Sambutan Rektor IKIP Mataram Sekaligus Penjelasan Kebijakan } \\
\text { dan Program IKIP Mataram (uraian Kiat-kiat Penulisan Artikel } \\
\text { Ilmiah pada Jurnal Nasional dan Internasional) }\end{array}$ & $\mathrm{PL}$ & $\begin{array}{l}\text { Prof. Kusno, DEA, } \\
\text { P.hD }\end{array}$ \\
\hline $11.00-11.30$ & $\begin{array}{l}\text { Penyampaian Informasi tentang Program Magister (S2) } \\
\text { Pendidikan Bahasa Inggris }\end{array}$ & $0.5 \mathrm{JPL}$ & Dr. Ari Rahman, M.Pd \\
\hline $11.30-12.40$ & $\begin{array}{l}\text { Dasar-Dasar dan Tata Cara Penulisan Karya Ilmiah yang Baik dan } \\
\text { Benar dalam Ilmu Bahasa }\end{array}$ & $2 \mathrm{JPL}$ & Dr. Arif Rahman, M.Pd \\
\hline $12.45-13.30$ & ISHOMA & - & - \\
\hline $13.30-14.00$ & $\begin{array}{l}\text { Kegiatan Lanjutan: } \\
\text { Prosedur Pengajuan artikel ilmiah pada Jurnal Ilmiah di (JOLLT } \\
\text { \& JOeLT) IKIP Mataram }\end{array}$ & $1 \mathrm{JPL}$ & Dr. L. Ari Irawan, M.Pd \\
\hline \multirow[t]{2}{*}{$14.00-15.30$} & $\begin{array}{l}\text { Tata Cara Penulisan Karya } \text { Ilmiah yang Baik dan Benar: } \\
\text { OrganisasiSistematika } \quad \text { Karangan } \\
\text { 1. Penelitian PTK (Penelitian Tindakan Kelas) } \\
\text { 2. Penelitian Experimen } \\
\text { 3. Penelitian R \& D (Research and Desain) } \\
\end{array}$ & 2JPL & $\begin{array}{l}\text { 1. Dr. Jupri, M.Pd } \\
\text { 2. Dr. L. Ari Irawan, } \\
\text { M.Pd } \\
\text { 3. Dr.Haerazi, M.Hum } \\
\end{array}$ \\
\hline & $\begin{array}{l}\text { Pengalaman Menulis dan Mepublikasikan Artikel Ilmiah Pada } \\
\text { Jurnal Nasional dan Internasional }\end{array}$ & & Dr. I Ketut Warta, MS \\
\hline $15.30-16.30$ & Coffe Break & & Panitia \\
\hline $16.30-17.30$ & $\begin{array}{l}\text { Praktik Menulis Karangan Ilmiah(Penulisan artikel ilmiah dalam } \\
\text { bahasa Inggris yang baik dan benar) }\end{array}$ & 2.JPL & $\begin{array}{ll}\text { Tim. } & \text { Dosen } \\
\text { Pascasarjana } & \\
\end{array}$ \\
\hline - & Pembimbingan Lanjutan & 30 JPL & $\begin{array}{ll}\text { Tim. } & \text { Dosen } \\
\text { Pascasarjana } & \\
\end{array}$ \\
\hline - & Jumlah Total Jam & 38 JPL & - \\
\hline
\end{tabular}

\section{Hasil Pelaksanaan Kegiatan}

Jika mengacu pada pelaksanaan kegiatan pendampingan yang telah dilaksanakan, maka dapat diketahui hasil kegiatan pendampingan ini mencakup beberapa komponen, yaitu: (1) kemauan peserta dalam menulis artikel atau karya tulis ilmiah adalah cukup tinggi; (2) pemahaman peserta terhadap menulis artikel adalah kurang; dan (3) pemahaman peserta terhadap jenis tulisan adalah kurang. Berdasarkan hasil temuan dari kegiatan pendampingan yang telah dilakukan, dapat diketahui bahwa 
pendampingan ini berjalan dengan lancar dan mencapai tujuan kegiatan. Indikatornya adalan bertambahnya pemahaman guru dalam menulis artikel. Peserta sangat antusias dalam mengikuti kegiatan pendampinganpenulisan artikel ini. Hal ini dapat diketahui dari banyaknya pertanyaan yang diajukan oleh peserta pada saat kegiatan pendampingan.

Beberapa pertanyaan yang muncul pada saat sesi pemaparan materi dari narasumber adalah: (1) perbedaan artikel hasil riset dengan artikel setara hasil penelitian atau kajian gagasan; (2) perbedaan artikel ilmiah dengan artikel popular; (3) cara menyusun judul penelitian yang menarik; (4) cara menulis abstrak; (5) cara menulis pendahuluan dan metode dalam artikel; (6) cara menulis pembahasan dalam artikel; (7) proses mengirim artikel ke jurnal ilmiah; dan (8) cara menyikapi pengelola jurnal ketika tak kunjung ada kabar artikel yang akan diterbitkan. Guru pada dasarnya memiliki keinginan yang kuat untuk menulis, namun ada permasalahan yang mengganjal guru dalam menulis. Berdasarkan hasil focus group discussion (FGD) beberapa hal yang menjadi permasalahan gurudalam menulis artikel seperti yang ditampilkan pada Tabel 5.2. Permasalahan tersebut dibagi menjadi dua, yaitu masalah yang bersifat eksternal dan internal.

\section{SIMPULAN}

Berdasarkan pelaksanaan kegiatan pendampingan ini, disimpulkan: (1) kemauan peserta dalam menulis artikel atau karya tulis ilmiah adalah cukup tinggi; (2) pemahaman peserta terhadap menulis artikel adalah kurang; dan (3) pemahaman peserta terhadap jenis tulisan adalah kurang. Hasil FGD menujukkan permasalahan yang dialami guru dalam menulis karya ilmiah. Permasalahan yang dialami oleh guru dalam menulis karya ilmiah diklasifikasikan menjadi dua, yaitu masalah eksternal dan masalah internal.

Masalah eksternal guru dalam menulis karya ilmiah adalah: (1) kurangnya informasi tentang hal-hal berkaitan dengan menulis; (2) sulitnya menemukan tempat bertanya ketika menulis; (3) keterbatasan referensi dalam menulis; dan (4) proses birokrasi (dibatasi satu jenis tulisan, seperti hasil PTK). Masalah internal guru dalam menulis karya ilmiah adalah: (1) lemahnya budaya menulis di kalangan para guru; (2) rendahnya motivasi guru untuk membuat karya tulis artikel ilmiah; (3) sebagian guru memandang proses birokrasi yang selalu mempersulit membuat mereka menyerah sebelum berusaha; dan (4) keterbatasan waktu untuk menulis.

\section{Saran}

Berdasarkan hasil kegiatan pendampingan, saran yang diajukan adalah bagi guru dan Kepala SMP-SMA Kabupaten Lombok Tengah, hendaknya menjalin kerjasama dengan perguruan tinggi. Bentuk kerjasama ini adalah berupa pembimbingan dari perguruan tinggi kepada para guru dalam menyusun karya tulis ilmiah. Kepala sekolah disarankan membentuk forum ilmiah guru yang merupakan wahana para guru dalam berdiskusi, seminar ilmiah, ataupun diseminasi karya ilmiahnya.

Saran bagi para guru adalah mengirimkan artikel penelitiannya ke kegiatan seminar nasional yang menerbitkan prosiding. Hal ini merupakan langkah awal yang dapat dilakukan oleh guru untuk mengasah kemampuan menulisnya. Setelahmengikuti seminar nasional, para guru disarankan mengirimkan artikel ilmiahnya ke jurnal nasional, seminar internasional, dan bahkan jurnal internasional. Saran bagi pelaksana pengabdian selanjutnya, agar menyelenggarakan kegiatan workshop menulis karya tulis ilmiah, baik di wilayah SMP-SMA Kabupaten Lombok Tengah ataupun di wilayah lain, dengan menggunakan pendekatan pendampingan klinis (coaching clinic for writing).

\section{DAFTAR RUJUKAN}

Ecarnot, F., Seronde, M. F., Chopard, R., Schiele, F., dan Meneveau, N. 2015. Writing a Scientific Article: A Stepby-Step Guide for Beginners. European Geriatric Medicine, 27:1http://dx.doi.org/10.1016/j.eurger.2015. 08.005 .

Djariyo, Sulianto, J., Mudzanatun, Reffiane, F., dan Purnamasari, I. 2016. Pelatihan Penulisan Karya Ilmiah untuk 
Meningkatkan Keterampilan Menulis bagi Guru Sekolah Dasar di Kota Semarang,

(Online),(http://download.portalgaruda. org/article.php? article $=6992 \& v a l=531$ ), diakses 2 Desember 2016.

Fannies, S. A. 2016. Analisis Kesulitan Menulis Karya Ilmiah Sederhana Siswa Kelas IX SMPN 3 Singosari. Cendekia, 10(1): 19-28.

Fatah, A., Wakid, M., dan Yoga, N. A. 2015. Pelatihan

Penulisan

MakalahPendamping/Prosiding dalam Rangka Menghadapi Pelaksanaan Permenpan Nomor 16 Tahun 2009. Laporan Pengabdian kepadaMasyarakat tidak diterbitkan. Yogyakarta: Universitas Negeri Yogyakarta. (Online), (http://staff.uny.ac.id/sites/default/files/ pengabdian/nirmala-adhi-yogapambayun-mpd/pelatihan-penulisanmakalah-pendampingprosiding-dalamrangka-menghadapi-pelaksanaanpermenpan-nomor-.pdf), diakses 12 Januari 2017.

Gilinsky, A., Forbes, S. L., dan Reed, M. M. 2016. Writing Cases to Advance Wine Business Research and Pedagogy. Wine Economics and Policy, 5: 60-67. http://dx.doi.org/10.1016/j.wep.2016.04 .001 .

Gunawan, I. 2014. Metode Penelitian Kualitatif: Teori dan Praktik. Jakarta: PT Bumi Aksara.

Huang, J. C. 2017. What do Subject Experts Teach about Writing Research Articles? An Exploratory Study. Journal of English for AcademicPurposes, 25: 1829.

http://dx.doi.org/10.1016/j.jeap.2016.10 .004 .

Kemdikbud. 2017. Daftar Satuan Pendidikan (Sekolah) Per Kec. Lowokwaru, (Online), (http://referensi.data.kemdikbud.go.id/in dex11.php?kode $=0561 \quad$ 05\&level $=3$ ), diakses 11 Januari 2017.

Komara,A. 2017. Menulis Artikel dan Karya Ilmiah,

(Online), (http://www.lpmpjateng.go.id/web/inde x.php/arsip/artikel/174-menulis-artikeldan-karya-ilmiah), diakses 12 Januari 2017.

Larasati, R. T. 2014. Faktor-faktor Penghambat Penulisan Karya Tulis Ilmiahdalam Pengembangan Keprofesian Berkelanjutan Guru SDN Lempuyangwangi Yogyakarta. Tesis tidak diterbitkan. Yogyakarta:Universitas Negeri Yogyakarta. 